\title{
Spatial and Movement-Based Heuristics for Encoding Pattern Information Through Touch
}

\author{
Susan J. Lederman \\ Queen's University at Kingston, Kingston, \\ Ontario, Canada \\ Roberta L. Klatzky \\ University of California at Santa Barbara
}

\author{
Paul O. Barber
}

Queen's University at Kingston, Kingston, Ontario, Canada

\begin{abstract}
Seven experiments investigated the heuristics people use to encode spatial pattern information through touch. Observers traced a tangible pathway with one hand and then answered questions about either the euclidean line between the pathway endpoints or the pathway itself. Parameters of the euclidean line were held constant, while characteristics of the felt pathway were manipulated. Experiments 1-4 showed that blindfolded sighted and blind observers increasingly overestimated the length of the euclidean line as the length of the explored pathway increased. This indicates a movement-based heuristic for encoding distance. Experiments 5-7 indicated that judgments of the position of the euclidean line did not vary with the position of the felt pathway or the extent to which it deviated from that line. Instead, the results indicated that observers relied on implicit spatial axes, which are movement independent, to judge position. These and other results have implications for theories of haptic encoding of spatial pattern and for the construction of tangible graphics displays.
\end{abstract}

In the past few years there has been considerable interest in how people encode layout information in large-scale space (i.e., space that surrounds the observer; Ittelson, 1973) and how they update this information as they move about in their environment (e.g., Liben, Patterson, \& Newcombe, 1981; Rieser, Guth, \& Hill, 1982; Reiser, Lockman, \& Pick, 1980). These same questions are also important when considering how people interpret smallscale spatial layouts, which include various forms of graphics (maps, pictures, graphs, etc.) and three-dimensional objects or models.

This research was supported by Natural Sciences and Engineering Research Council of Canada Grant A9584 to the first author and by National Institute of Mental Health Grant MH25090 to the second author. The authors thank Cheryl O'Neill, Kathy Yeigh, and Georgia Manolakos for running Experiments 2 and 3 and Debbie Redding-Stewart for running Experiments 5-7. We also thank the Canadian National Institute for the Blind for making their facilities available to us in Toronto, and all the participants in Experiment 4 who gave us their time and suggestions.

Requests for reprints should be sent to S. J. Lederman, Department of Psychology, Queen's University, Kingston, Ontario, Canada K7L 3N6, or to R. L. Klatzky, Department of Psychology, University of California at Santa Barbara, Santa Barbara, California 93106.
Although the role of movement has been an important concern in studies of large-scale spatial encoding, it has been given relatively little attention in research on small-scale space, which has concentrated more on the contribution of vision. As a result, we do not know a great deal about how sighted and blind observers encode spatial patterns haptically; that is, through purposive touch.

Much of the earlier work on haptic pattern encoding focused on the relative accuracy of touch and vision, emphasizing the superiority of the latter (e.g., Cashdan, 1968; Lobb, 1965). Other research merely compared accuracy levels of blind and sighted observers without regard to qualitative processing differences between them (e.g., Cleaves \& Royal, 1979; Dodds, Howarth, \& Carter, 1982; Worchel, 1951). Only recently have more analytic approaches been adopted (e.g., Brambring, 1976; Kerr, 1983; Millar, 1975, 1981). In keeping with this more recent work, the current research also investigates the nature of haptically perceived spatial patterns in sighted and blind observers.

An important theoretical question is, what heuristics do people use in constructing a representation of a spatial layout from haptic 
input? The haptic system commonly, although not exclusively, gathers information by means of a sequence of exploratory contact movements over surfaces and contours. One potential heuristic, then, is to use aspects of the movements directly to infer the nature of the spatial layout. Evidence for this heuristic can be found both with small-scale patterns that are felt with the finger (Brambring, 1976; Millar, 1975, 1976, 1981) and with largescale layouts that are explored through movement (e.g., Book \& Garling, 1981; Kosslyn, Pick, \& Fariello, 1974; Rieser, Lockman, \& Pick, 1980; Sherman, Croxton, \& Smith, 1979). In general, these studies show that characteristics of the movements used in exploration of a display influence reproduction of or judgments about its spatial properties, such as the relative or absolute location of points or distances between them.

The influence of movement on spatial layout representation can be related to the cartographic distinction between two kinds of physical maps: route maps and survey maps (Downs \& Stea, 1977). A survey map is an overview in which all parts of the layout are directly accessible. A route map codes the layout as a set of temporal and spatial sequences. If a haptically explored layout is encoded in terms of the sequence of exploratory movements, its internal representation may be more like a route map. The speed and accuracy of access to such a representation are potentially tied to the particular set of movements used during the initial exploration; such effects are found in the studies cited earlier.

The literature on "cognitive mapping" of viewed displays is relevant to the question of haptic spatial representation because it identifies a number of heuristics that might be used to achieve a spatial representation. Clearly, at least some of these may be used for encoding spatial information obtained through the haptic system as well. Tversky (1981) has described heuristics that refer points on a map to natural spatial axes (horizontal and vertical). Explicit landmarks and reference points can also be used to represent locations (e.g., Lederman \& Taylor, 1969; Nelson \& Chaiklin, 1980; Sadalla, Staplin, \& Burroughs, 1979; Taylor, 1961). Another heuristic is to convert the density of points in space as an estimate of spatial extent-the "filled space illusion" (Thorndyke, 1981; Woodworth, 1938).

Whereas a movement-based heuristic can be used to produce an internal representation similar to a route map, the other heuristics just described can be used to produce a static spatial representation more like a survey map. Can these other heuristics be used with only haptic input? Prior research suggests that the use of external referents is possible. The ability to identify referents is severely decreased when the observer is deprived of sight, of course, but it is still possible to use discriminative tactual features (Lederman \& Taylor, 1969); spatial axes, or body parts (Millar, 1981; Wong, 1977). Congenitally blind individuals appear less able to make use of such referents than sighted or adventitiously blind individuals (for small-scale layouts, Millar, 1981; for large-scale layouts, Rieser et al., 1980). Thus, it appears to be more difficult for the blind to achieve an internal survey representation of a haptic input.

The use of heuristics in cognitive mapping has an important consequence: systematic distortions in the resultant representation. The strategy of using natural axes results in errors in relative location because people mentally align points along an axis (Tversky, 1981). Similarly, the use of filled space to estimate distance leads to overestimation of small filled spaces and underestimation of large unfilled ones (Thorndyke, 1981; Woodworth, 1938).

The study of haptic space perception has relevance for applied as well as theoretical issues, particularly for the effective design of tangible graphics displays for the blind. Although tangible graphics have been used on a fairly informal basis for educating young blind children, there has been relatively little systematic evaluation of these aids (see Schiff \& Foulke, 1982). Tangible graphics are usually raised replicas of original visual masters, apparently based on the assumption that whatever works for vision should be optimal for touch (see Berla, 1982; Lederman, 1979). However, this assumption should not be accepted without reservation, because modalityspecific encoding mechanisms have been found (e.g., O'Connor \& Hermelin, 1978). 
The present research begins with the assumption that haptic perceivers of small-scale displays adopt encoding heuristics to convert movement to spatial representations. If displays are such that a direct translation to visual imagery is not readily achieved (for example, they are larger than a finger span and unfamiliar in shape), movement-based strategies are particularly likely. For example, movement duration could be translated into an estimate of linear extent; a shape could be represented by the muscular actions needed to trace it, or a contour's extent could be measured by considering the joints that must be activated in order to move a finger along it (involvement of more proximal joints suggests longer contours). Such heuristics should lead to systematic and predictable patterns of error when exploratory movements do not directly reflect the to-be-reported attributes of a spatial display.

A different strategy is to adopt static reference points or axes and locate points on the pattern relative to those referents. We consider, in particular, pinpointing a position with one hand while judging other positions relative to it, and using natural spatial axes. These heuristics should not produce errors that are directly related to exploratory movements.

The principal concern of the present studies is with judgments of portions of a spatial layout that were not directly explored by the hand. The general task required observers to trace a tangible pathway with one hand and then to answer questions about an inferred path, consisting of the straight line between the pathway's endpoints (and in some cases about the explored pathway as well). This procedure made it possible to hold constant the parameters of the implicit line that would be judged while varying features of the explicitly felt pathway. If movement plays a role in encoding the inferred line, variations in the felt pathway should affect the reports. The first series of studies concerns judgments of the length of the inferred line, and the second series concerns judgments of its position.

\section{Haptic Perception of Distance}

The following studies investigated whether the judgment of the euclidean distance be- tween the start and end points of a tangible pathway would increase with the length of the pathway itself, as would be consistent with a movement-based heuristic. In addition to manipulating the length of the pathway and the euclidean distance between its endpoints, we used two modes of exploration. In the anchor mode, subjects kept one finger on the starting point of the pathway throughout exploration; in the no-anchor mode, the nonexploring hand was not used. This manipulation was intended to determine whether the provision of a static reference point (the anchor hand) would eliminate the movementbased heuristic.

\section{Experiments 1-3}

In Experiment 1, subjects judged either the length of the felt pathway or the euclidean distance on each trial, not knowing in advance which would be required. Pathway estimates were used primarily to focus observers' attention on their exploration of the entire pathway configuration. This study used a static placement response to indicate the judged distance. Experiment 2 used the same response, but required observers only to judge the euclidean distance, in order to determine whether they could ignore their movements and just focus on the pathway endpoints, thus eliminating effects of pathway distance. Experiment 3 was identical to Experiment 2 except for the use of a dynamic tracing response, more similar to the movements used in exploration than a static placement response.

\section{Method}

Observers. In each experiment, 12 men and 12 women participated for payment. The observers were different in each experiment. All were normally sighted, right-handed members of psychology classes at Queen's University and were naive as to the purpose of the experiment.

Apparatus and stimuli. For each of five euclidean distances $(2.5,4.1,6.7,11.0$, and $15.2 \mathrm{~cm}$ ), five pathway distances were designated $(1,2,4,6$, and 8 times the euclidean distance). At pathway distance level 1 , the pathway was a straight line. The configurations of the 20 curved pathways corresponding to the other pathway distances were curved lines that could be traced with one hand while the other remained on the starting point. (The two hands never touched beyond the start.) Each pathway was pressed into a Brailon plastic sheet with a stylus (Letraset Canada Model B-1), creating a pathway of raised dots about $2 \mathrm{~mm}$ in diameter and separated by 
about $3 \mathrm{~mm}$. The start and end points of the pathway were marked with small sandpaper squares. The resulting 25 patterns were oriented so that the euclidean (straight) line between the pathway endpoints was oriented across a variety of vertical, horizontal, and oblique positions (relative to the horizontal table edge in front of the subject).

A board $194 \mathrm{~cm}$ in length was mounted $23 \mathrm{~cm}$ above and parallel to the table edge. In Experiments 1 and 2, observers indicated their distance estimates by anchoring their left hand on a small marker toward the left end of the board and placing their right index finger to the right (without sliding it along the board) so that the interfinger distance represented their judgment of extent. In Experiment 3, the observer placed the left index finger on the marker and the right index finger was placed beside it. The right index finger was then moved along the board until the distance moved matched the euclidean estimate.

Procedure. Observers were blindfolded. On no-anchor trials, the experimenter placed the observer's right index finger on the start square. The observer traced the pathway to the end and could then retrace it back and forth as often as desired. On anchor trials, the observer's left index finger was placed on the start and the right index finger slid over it and traced the pathway as in no- anchor trials. Immediately after exploration, the observer made either a euclidean judgment (i.e., of the length of the straight line between start and end points) or (in Experiment 1 only) a judgment of the length of the actually explored pathway. In Experiment 1, half of the observers of each gender made both judgments about all stimuli by using an anchor in the first session and no anchor in the second session; the remaining observers had sessions in the reverse order. In Experiments 2 and 3, observers made euclidean judgments about all 25 stimuli by using both modes of exploration in a single session. The 50 trials in a session were randomly ordered and lasted about $\mathbf{l ~ h r}$.

\section{Results}

Euclidean errors. All three studies showed that judgments of euclidean distance increased with pathway length, even when subjects used one finger as an anchor, for both static and dynamic responses. The magnitude of this effect was reduced when observers knew in

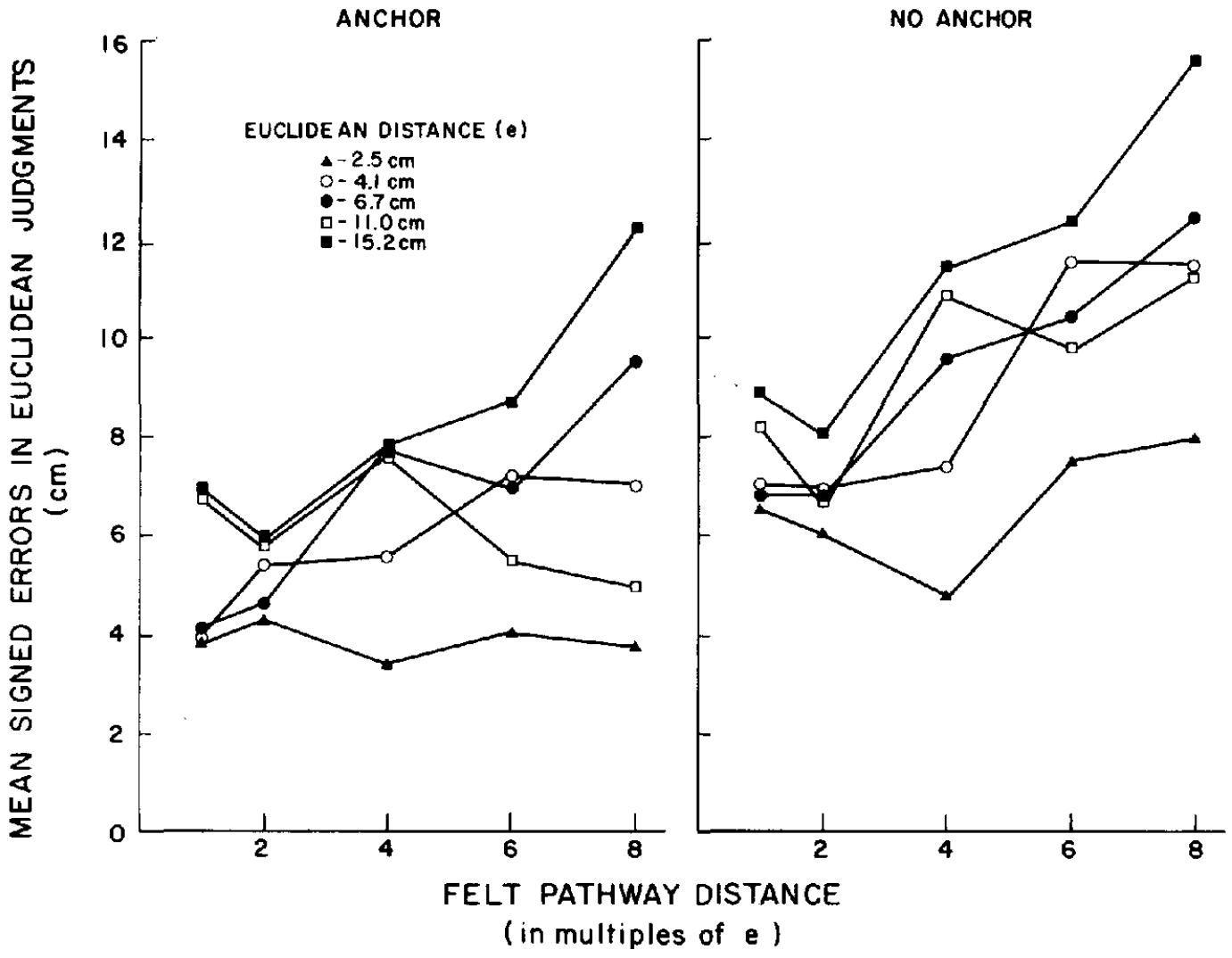

Figure 1. Experiment 1: Mean signed errors in euclidean judgments as a function of pathway distance. for each euclidean distance and mode of exploration (anchor, no anchor). (When pathway distance $=1 \mathrm{e}$, the pathway is the euclidean line.) 
advance that they were to judge the euclidean distance.

Figure 1 shows the euclidean errors (reported distance minus true distance) in Experiment 1 for each combination of pathway and euclidean distance, by exploratory mode. Tables 1 and 2 show the corresponding results for Experiments 2 and 3 as well as the average error for each euclidean distance and each pathway distance.

Table 3 reports $F$ values for significant effects $(p<.05)$ in the analysis of euclidean errors. (This table is not intended to address the magnitude of the effects.) The trends are as follows: In all three studies, euclidean errors increased with increasing pathway distance. The effect of pathway distance on absolute errors was greatest in Experiment 1, where either euclidean or pathway distance was tested. However, Experiments 2 and 3 showed strong relative effects (8e: 1e error values), particularly for the $15.2-\mathrm{cm}$ euclidean distance.

In Experiment 1, signed euclidean errors were higher in the no-anchor than in the anchor condition. However, in Experiments 2 and 3, errors were higher in the anchor condition than they were in the no-anchor

Table 1

Experiment 2: Errors on Euclidean Distance Judgments by Euclidean Distance, Pathway Distance, and Mode of Exploration

\begin{tabular}{|c|c|c|c|c|c|c|}
\hline \multirow{2}{*}{$\begin{array}{c}\text { Euclidean } \\
\text { distance }\end{array}$} & \multicolumn{6}{|c|}{ Pathway distance } \\
\hline & $\mathrm{e}$ & $2 \mathrm{e}$ & $4 \mathrm{e}$ & $6 e$ & $8 \mathrm{e}$ & Ave. \\
\hline \multicolumn{7}{|c|}{ Anchor } \\
\hline $\begin{array}{r}2.5 \\
4.1 \\
6.7 \\
11.0 \\
15.2 \\
\text { Ave. }\end{array}$ & $\begin{array}{l}2.84 \\
2.11 \\
2.67 \\
2.28 \\
2.52 \\
2.48\end{array}$ & $\begin{array}{l}3.50 \\
3.32 \\
3.37 \\
3.12 \\
0.44 \\
2.75\end{array}$ & $\begin{array}{l}2.01 \\
3.71 \\
4.95 \\
2.98 \\
2.69 \\
3.27\end{array}$ & $\begin{array}{l}2.95 \\
4.56 \\
2.00 \\
1.45 \\
2.87 \\
2.76\end{array}$ & $\begin{array}{l}2.73 \\
4.89 \\
3.66 \\
0.12 \\
4.32 \\
3.14\end{array}$ & $\begin{array}{l}2.81 \\
3.72 \\
3.33 \\
1.99 \\
2.57\end{array}$ \\
\hline \multicolumn{7}{|c|}{ No anchor } \\
\hline $\begin{array}{r}2.5 \\
4.1 \\
6.7 \\
11.0 \\
15.2 \\
\text { Ave. }\end{array}$ & $\begin{array}{l}2.94 \\
2.73 \\
3.28 \\
1.20 \\
0.81 \\
2.19\end{array}$ & $\begin{array}{r}2.81 \\
2.55 \\
2.85 \\
1.79 \\
-1.19 \\
1.76\end{array}$ & $\begin{array}{l}1.65 \\
2.97 \\
4.18 \\
2.05 \\
0.21 \\
2.21\end{array}$ & $\begin{array}{r}2.76 \\
5.08 \\
3.02 \\
1.41 \\
-0.23 \\
2.41\end{array}$ & $\begin{array}{r}3.45 \\
4.08 \\
4.65 \\
-0.55 \\
3.40 \\
3.00\end{array}$ & $\begin{array}{l}2.72 \\
3.48 \\
3.60 \\
1.18 \\
2.31\end{array}$ \\
\hline
\end{tabular}

Note. Ave. = average error.
Table 2

Experiment 3: Error on Euclidean Distance Judgments by Euclidean Distance, Pathway Distance, and Mode of Exploration

\begin{tabular}{|c|c|c|c|c|c|c|}
\hline \multirow{2}{*}{$\begin{array}{c}\text { Euclidean } \\
\text { distance }\end{array}$} & \multicolumn{6}{|c|}{ Pathway distance } \\
\hline & e & $2 \mathrm{e}$ & $4 e$ & $6 e$ & $8 \mathrm{e}$ & Ave. \\
\hline \multicolumn{7}{|c|}{ Anchor } \\
\hline 2.5 & 1.96 & 2.02 & 0.62 & 1.34 & 1.52 & 1.49 \\
\hline 4.1 & 1.85 & 2.37 & 2.52 & 2.71 & 3.92 & 2.67 \\
\hline 6.7 & 1.13 & 1.45 & 2.78 & 0.88 & 2.39 & 1.73 \\
\hline 11.0 & 1.09 & 1.58 & 1.45 & -0.88 & -0.88 & 0.47 \\
\hline 15.2 & 0.36 & 0.20 & 1.56 & 1.82 & 3.13 & 1.41 \\
\hline Ave. & 1.28 & 1.52 & 1.79 & 1.17 & 2.00 & \\
\hline \multicolumn{7}{|c|}{ No anchor } \\
\hline 2.5 & 2.20 & 1.66 & 0.71 & 1.96 & 2.05 & 1.72 \\
\hline 4.1 & 1.65 & 1.73 & 2.04 & 3.70 & 2.97 & 2.42 \\
\hline 6.7 & 0.94 & 1.17 & 2.42 & 2.01 & 2.68 & 1.84 \\
\hline 11.0 & 0.94 & 0.48 & 1.28 & 1.02 & -0.95 & 0.35 \\
\hline 15.2 & -0.93 & -1.60 & 0.14 & -0.18 & 3.98 & 0.28 \\
\hline Ave. & 0.96 & 0.69 & 1.32 & 1.70 & 2.15 & \\
\hline
\end{tabular}

Note. Ave. = average error.

condition, but were significant in Experiment 2 only. The important point is that the anchor therefore did not consistently reduce error.

The main effect of euclidean distance was significant in all three studies, but the effects were inconsistent. In Experiment 1, signed error increased with euclidean distance, whereas in Experiments 2 and 3 the five functions relating euclidean judgment error to pathway distance were more tightly clustered together.

There were also several two-way interactions that should be considered. First, estimated euclidean distance tended to decrease anomalously with pathway distance when the $11-\mathrm{cm}$ euclidean distance stimuli were presented. We cannot explain the reasons for this, other than that it may reflect a stimulus artifact. Second, the pathway distance effect tended to increase with euclidean distance in Experiment 1; the effect was somewhat less regular in Experiments 2 and 3, but in all three cases the pathway distance by euclidean distance interaction was statistically significant. Third, the pathway by mode interaction was significant in Experiments 1 and 3, indicating a reduction in the magnitude of the pathway distance effect when an anchor was used. 
Table 3

Experiments 1-3: F values for Significant Effects on the Euclidean Error Measure

\begin{tabular}{|c|c|c|c|c|c|c|c|}
\hline Experiment & $\begin{array}{l}\text { Pathway } \\
\text { distance, } \\
F(4,88)\end{array}$ & $\begin{array}{l}\text { Euclidean } \\
\text { distance, } \\
F(4,88)\end{array}$ & $\begin{array}{c}\text { Mode of } \\
\text { exploration, } \\
F(1,22)\end{array}$ & $\begin{array}{c}\mathrm{P} \times \mathrm{E} \\
F(16,352)\end{array}$ & $\begin{array}{l}P \times M, \\
F(4,88)\end{array}$ & $\begin{array}{l}M \times E \\
F(4,88)\end{array}$ & $\begin{array}{l}\text { Gender, } \\
F(1,22)\end{array}$ \\
\hline 1 & 20.45 & 15.17 & 22.67 & 4.82 & 4.23 & & 7.51 \\
\hline 2 & 4.10 & 9.15 & 5.81 & 9.97 & & 7.94 & \\
\hline 3 & 5.31 & 8.50 & & 8.99 & 4.02 & 3.74 & \\
\hline
\end{tabular}

Note. $\mathbf{P} \times \mathbf{E}=$ Pathway $\times$ Euclidean Distance; $\mathrm{P} \times \mathbf{M}=$ Pathway $\times$ Mode of Exploration; and $\mathbf{M} \times \mathbf{E}=\mathbf{M o d e}$ of Exploration $\times$ Euclidean Distance.

Pathway errors. Errors (reported minus true distance) in judgments of the pathway distance in Experiment 1 were affected only by pathway length, as defined by the combination of euclidean distance, $F(4,88)=$ 10.12 , and pathway distance, $F(4,88)=$ 23.84; for the interaction, $F(16,352)=13.03$, ps $<.0001$. Figure 2 shows that the pathway estimates tend to follow Weber's law.

\section{Experiment 4}

Experiments 1-3 support the hypothesis that a movement-based heuristic is used to estimate distances in a haptically explored pattern. One might expect similar strong effects of pathway exploration with blind subjects, who may have even less recourse to nonmovement-based heuristics that make use of external referents (Millar, 1981). Accordingly, Experiment 4 assessed whether blind (congenital and adventitious) subjects would systematically overestimate euclidean extent as a function of increasing length of an explored pathway.

\section{Method}

Observers. Thirty totally blind (i.e., only perception of light, but not of form or movement) adults participated. Ten of these observers were congenitally blind and the other 20 lost their sight some time after birth. Table 4 shows their attributes on several variables. Causes of blindness included diabetic retinopathy, retrolentalfibroplasia, retinoblastoma, cataracts, glaucoma, encephalitis (uncertain), unknown fungus, iritis, detached retina, macular degeneration, accident, cone disturbance, and microopthalmus. Only one observer had irregular periph-

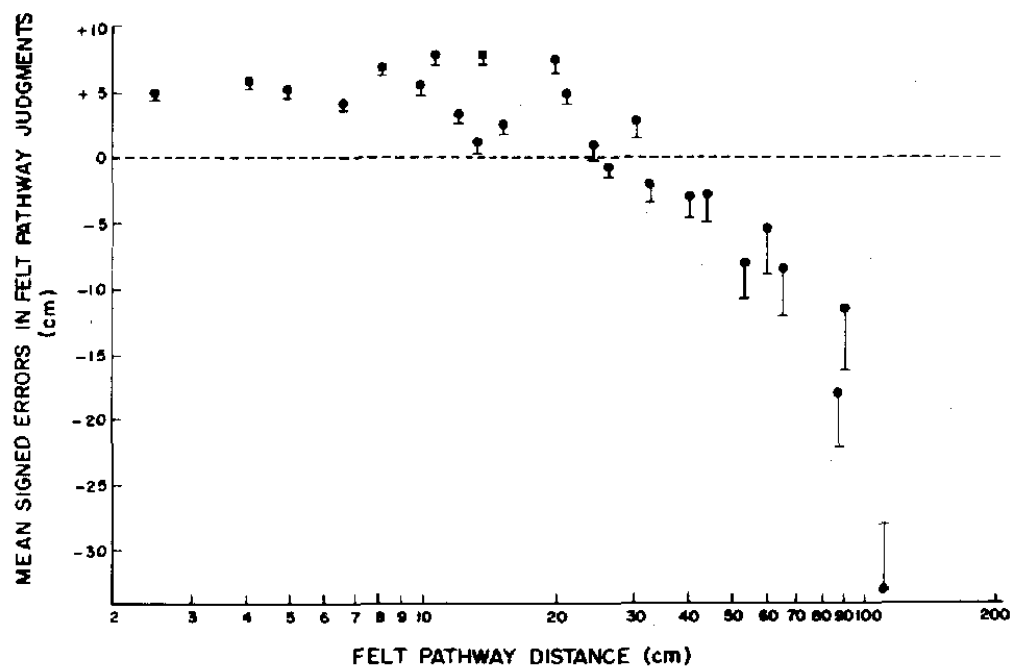

Figure 2. Experiment 1: Mean signed errors in pathway judgments as a function of pathway distance; bars indicate one standard error of the mean. 
eral neuropathy, and he had normal sensation at the time of testing. Only three observers had not completed high school.

Procedure. The apparatus and stimuli were like those used in the previous experiments. Observers were run at the Canadian National Institute for the Blind in Toronto or in their homes, in one session for about $2 \mathrm{hr}$. It consisted of a number of practice trials and 72 test trials: 3 euclidean distances $(2.5,6.7$, and $15.2 \mathrm{~cm}), 3$ pathway distances ( 1,4 , and 8 times euclidean), 2 modes of exploration (anchor, no-anchor), 2 judgments (euclidean or pathway distance), and 2 types of instruction (subjects were told which judgment to make either before or after exploring the stimulus pathway). The order of conditions was random. A tracing response was used, as in Experiment 3.

\section{Results}

The blindness data were variable enough that it seemed unwise to use multiple regression techniques in the analysis. Instead, subjects were split into two groups according to whether they were congenitally blind (i.e.,

Table 4

Experiment 4: Characteristics of Subjects

\begin{tabular}{|c|c|c|c|c|}
\hline $\begin{array}{l}\text { Subject } \\
\text { number }\end{array}$ & Sex & $\begin{array}{l}\text { Age } \\
\text { (yrs) }\end{array}$ & $\begin{array}{c}\text { Age } \\
\text { at onset }\end{array}$ & $\begin{array}{l}\text { Years } \\
\text { blind }\end{array}$ \\
\hline 1 & $\mathbf{M}$ & 38 & 29 & 9 \\
\hline 2 & $\mathrm{~F}$ & 29 & birth & 29 \\
\hline 3 & F & 20 & 2 & 18 \\
\hline 4 & $F$ & 45 & birth & 45 \\
\hline 5 & $\mathbf{M}$ & 52 & 25 & 27 \\
\hline 6 & $\mathbf{M}$ & 33 & 25 & 8 \\
\hline 7 & $\mathbf{M}$ & 35 & 12 & 23 \\
\hline 8 & $\mathbf{M}$ & 63 & 48 & 15 \\
\hline 9 & $\mathbf{M}$ & 42 & 1 & 41 \\
\hline 10 & $\mathbf{M}$ & 33 & 18 & 15 \\
\hline 11 & $\mathbf{M}$ & 35 & 16 & 19 \\
\hline 12 & $\mathbf{M}$ & 32 & birth & 32 \\
\hline 13 & $\mathbf{F}$ & 32 & 2 & 30 \\
\hline 14 & $\mathbf{M}$ & 28 & birth & 28 \\
\hline 15 & $\mathbf{M}$ & 18 & birth & 18 \\
\hline 16 & $\mathbf{M}$ & 48 & 44 & 4 \\
\hline 17 & $\mathbf{M}$ & 54 & 45 & 9 \\
\hline 18 & $\mathbf{M}$ & 25 & 24 & 0.5 \\
\hline 19 & $\mathbf{M}$ & 27 & 25 & 2 \\
\hline 20 & F & 31 & birth & 31 \\
\hline 21 & $\mathbf{M}$ & 30 & 6 & 24 \\
\hline 22 & $F$ & 65 & 64 & 0.75 \\
\hline 23 & $\mathbf{M}$ & 23 & 20 & 3 \\
\hline 24 & $F$ & 45 & birth & 45 \\
\hline 25 & $F$ & 30 & 11 & 19 \\
\hline 26 & $\mathbf{F}$ & 24 & birth & 24 \\
\hline 27 & $\mathbf{M}$ & 32 & birth & 32 \\
\hline 28 & $\mathbf{F}$ & 35 & birth & 35 \\
\hline 29 & $\mathbf{F}$ & 29 & 28 & 1 \\
\hline 30 & F & 33 & 1 & 32 \\
\hline
\end{tabular}

blind from birth, $n=10$ ) or adventitiously blind $(n=20)$. Analyses of variance (ANOVAs) (signed euclidean errors; signed pathway errors) included this 2-level factor along with pathway distance, euclidean distance, time of instruction, and exploration mode.

Euclidean errors. As in Experiments 1-3, judgments of euclidean distance increased with pathway length, regardless of the mode of exploration (anchor vs. no-anchor). This result is indicated by the highly significant pathway effect, $F(2,56)=16.77, p<.0001$. The effect of euclidean distance was also statistically significant, but tended to vary by group. Thus, distance estimates increased with increasing euclidean distance for the congenitally blind, $F(2,18)=6.56, p<.01$; however, distance estimates initially increased and then slightly decreased as a function of euclidean distance for the adventitiously blind, $F(2,38)=5.31, p<.01$. This is because observers tended to increasingly underestimate the $15.2-\mathrm{cm}$ euclidean distances. The interaction term, pathway length by euclidean length, was also significant, $F(4,12)=4.04$, $p<.005$, indicating as before that the pathway effect tended to increase with increasing euclidean distance. These results have been plotted in Figure 3. The left panel shows signed errors in euclidean judgments for the congenitally blind as a function of pathway distance and euclidean distance and the right panel shows the corresponding data for the adventitiously blind. Errors were greater overall for the congenitally blind than they were for the adventitiously blind, $F(1,28)=4.17$, $p<.05$. The pathway distortion effect was clearly evident in both groups, although more pronounced in the congenitally blind observers.

The effect of anchor was not statistically significant, although the pattern of results was similar to that of Experiment 1; that is, the anchor condition resulted in fewer errors and less variability. Knowledge about the type of judgment to be made interacted significantly with euclidean distance, $F(2,56)=$ $5.22, p<.01$. In general, prior knowledge of the response type reduced error, but only for the 15.2-cm euclidean distances.

Pathway errors. Errors (reported minus true distance) in judgments of the pathway distance were affected by pathway length, as 

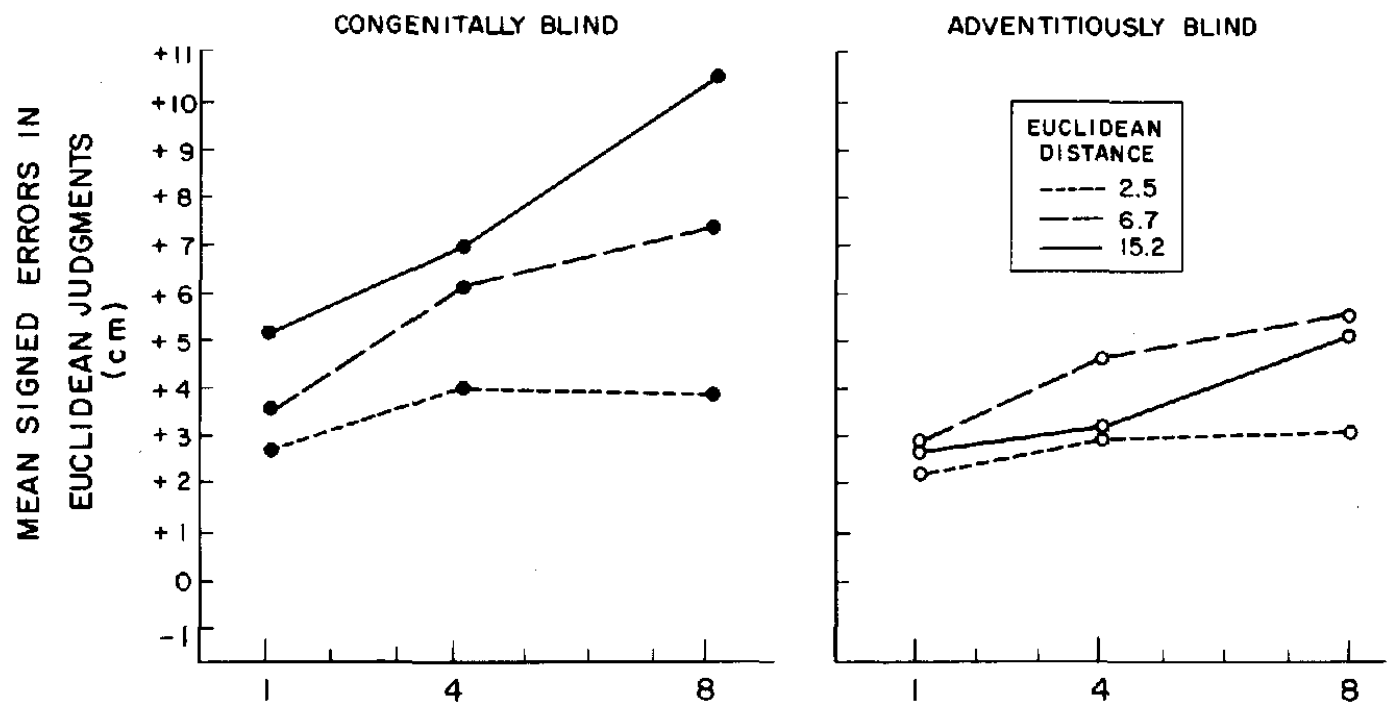

FELT PATHWAY DISTANCE

(in multiples of euclidean distance)

Figure 3. Experiment 4: Mean signed errors in euclidean judgments as a function of pathway distance, for each euclidean distance and each group (congenitally and adventitiously blind).

defined by the combination of euclidean distance and pathway distance as a single variable, $F(8,224)=30.12, p<.0001$. As in Experiment 1, errors tended to be overestimates for the shorter extents up to about 20$40 \mathrm{~cm}$ and underestimates beyond that range. These results are shown in Figure 4; errors in pathway distance judgments are plotted as a function of felt pathway distance for both blindness groups. Observers were more accurate when told which of the two judgments would be required before (as opposed to after) the exploration phase, but particularly for the two longest pathways; this was indicated by a significant Pathway Distance $X$ Time-of-Instruction interaction, $F(8,224)=$ $3.70, p<.0005$. There were no differences in the accuracy with which the two blindness groups estimated the length of the pathways traced. No other effects in either analysis were statistically significant.

\section{Haptic Perception of Position}

Experiments 1-4 demonstrated that observers used a movement-based strategy when estimating the extent of inferred euclidean distance. Specifically, they increasingly over- estimated the length of an inferred straightline path as the extent of the pathway traced increased. Experiments 5-7 investigated the possibility that observers also used a movement-based heuristic when judging inferred position. Experiment 5 was intended to translate the variables of the distance experiments directly into manipulations of position. Effects of movement-related varibles on judgments of position did not, however, parallel those of corresponding variables in Experiments 14. In fact, only one movement-related effect was obtained, and that was potentially attributable to the use of static spatial referents that varied with exploratory movements. Together, Experiments 6 and 7 verified that the obtained effect was due to a spatial-referent rather than to a movement-based heuristic.

\section{Experiment 5}

In this study, subjects judged the position (cf. euclidean distance in Experiments 1-4) of the inferred straight line joining the start and end points of each dotted line configuration that they explored. The direction and "detour" (maximum perpendicular) distance of the pathway (cf. pathway distance in pre- 


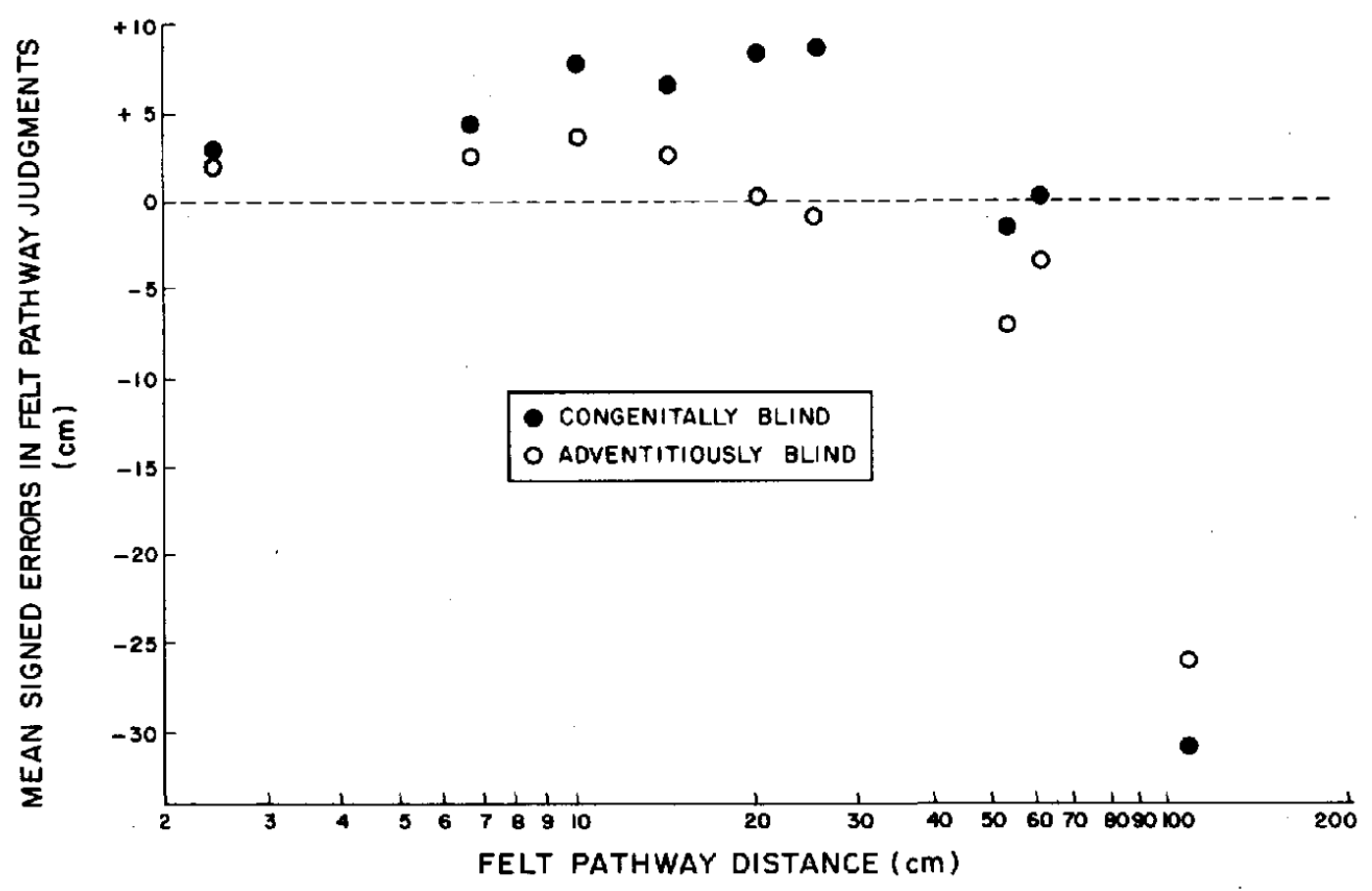

Figure 4. Experiment 4: Mean signed errors in pathway judgments as a function of pathway distance, for each group (congenitally and adventitiously blind).

vious experiments) from the inferred line were manipulated. If a movement-based heuristic were used, judgments of inferred position would be distorted in the direction of the movements used to explore the pattern. Further, the magnitude of the distortion should increase with the detour distance of the pathway from the inferred line.

\section{Method}

Observers. The normally sighted observers were 10 male and 10 female students in introductory psychology at the University of California, Santa Barbara (UCSB). They received credit toward a course requirement or were paid for participating.

Stimuli. The stimuli were raised dot pathways formed as in the previous studies. Figure 5 depicts a typical stimulus. The start (S) and end (E) points were always $6.7 \mathrm{~cm}$ apart in a straight line and were marked with sandpaper circles. The end point bisected a $3.8-\mathrm{cm}$ reference line made of fine dots $(1 \mathrm{~mm}$ in diameter and $2 \mathrm{~mm}$ apart); it was positioned parallel to the table edge in front of the observer. There were 24 stimuli, each representing a unique combination of levels of three factors.

The first factor was the region of the hemiplane above the reference line in which the direct line (SE) fell. Its position is specified by direct angle (SER). (All angles are measured relative to the right horizontal vector ER.) The direct angle was randomly selected within the region $31-70^{\circ}, 71-110^{\circ}$, or $111-150^{\circ}$. The second stimulusdefined factor was the direction in which the pathway departed from the start of the direct line. It could be

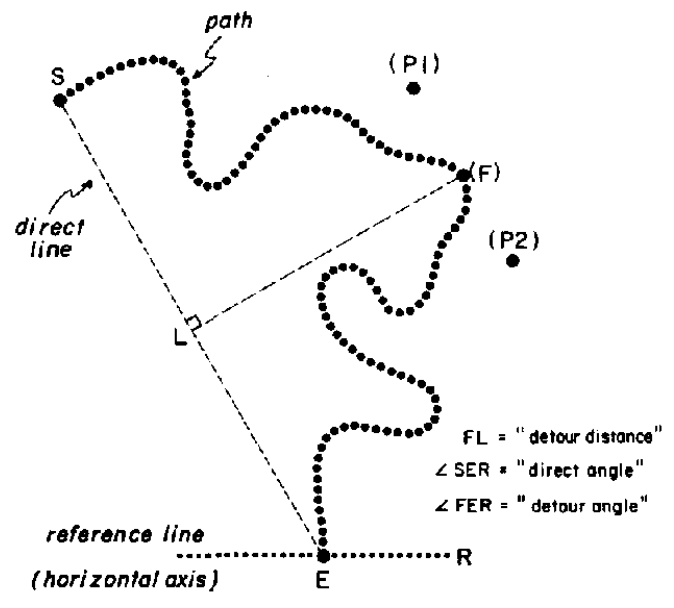

(table odge)

Figure 5. Experiment 5: Sample pathway configuration. (Points P1 and P2 were not in the actual displays.) 
either clockwise (as in Figure 5) or counterclockwise. The stimuli with clockwise pathways were reflections along a vertical axis of those with counterclockwise pathways. The third factor was detour distance (FL): the maximum perpendicular distance of the pathway from the direct line. The dot $F$ (unmarked on actual displays) on the pathway, which was farthest from the direct line, was located so that its perpendicular projection intersected within the middle $50 \%$ of SE. The detour distance factor had four levels in geometric increments: $2.5,6.7,11$, and $17.9 \mathrm{~cm}$. A pathway can be schematized as a perturbation about the trapezoid S-P1-P2-E in Figure 5. The points $P 1, P 2$, and $F$ lie along a line parallel to $S E ; P 1$ and $P 2$ are perpendicular to the $1 / 4$ and $3 / 4$ points of $S E$, respectively. The length of each pathway was arbitrarily set as twice the distance S-P1-P2-E. Thus pathway lengths for the four levels of detour distance were 18.7, $34.3,51.1$, and $78.7 \mathrm{~cm}$. There were also three straightline stimuli, for which the pathway was in fact the direct line SE, one in each region.

Procedure. Observers were blindfolded. On each trial, the observer examined a stimulus as in Experiments 14. As previously, he or she was allowed to feel the pathway from end to end as many times as desired. The experimenter then instructed the observer to judge the position of either the direct line (from the end point $\mathrm{E}$ to the start point $S$ ) or the detour line (from $E$ to $F$, the furthest point on the path).

Responses were made by setting a pointer, the fixed end of which was centered on a reference line mounted on a response board. The free end of the pointer touched a circular protractor, from which response angles were read. To prevent use of absolute spatial position in responding, this apparatus was on a table to the observer's right so that it was necessary to swivel rightward to respond. The observer was to pretend that the fixed end of the pointer was at the end of the pathway and that the reference line on the response board was the same reference line as originally examined. For the direct-line judgments, the subject was to set the pointer toward the start point on the pathway; for the detour-line judgments, the subject was to point toward the farthest detour point on the pathway. The instructions and feedback during practice trials made it clear that the farthest point was the one that deviated most from the direct line along a perpendicular.

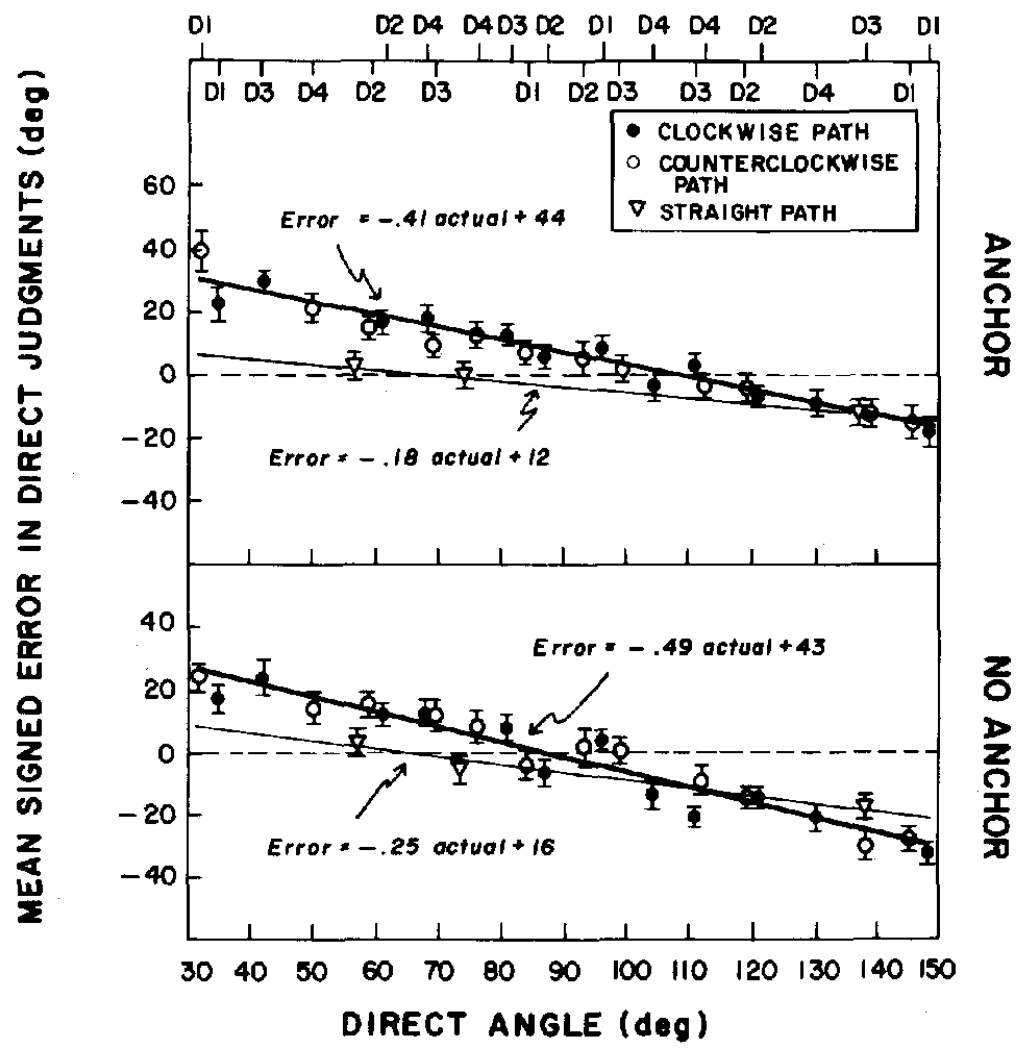

Figure 6. Experiment 5: Mean signed errors in judgments of angular position of the direct line (positive error is an overshoot; negative error is an undershoot) as a function of the true direct angle, for each mode of exploration (anchor, no anchor). (The symbol at the top of the graph indicates the detour distance for the stimulus having the corresponding direct angle, D1 $=2.5 \mathrm{~cm}, \mathrm{D} 2=6.7 \mathrm{~cm}, \mathrm{D} 3=11 \mathrm{~cm}, \mathrm{D} 4=17.9$ $\mathrm{cm}$. Bars indicate one standard error of the mean. Separate functions are shown for straight vs. curved paths.) 
Both judgments were made for each of the 24 curvedpathway stimuli by using both the anchor and no-anchor modes of exploration. For each of the three straight-line stimuli, only the direct-line judgment was made (because there was no detour from the straight line). Thus there was a total of 102 trials, distributed over two to three 1hr sessions in random order. The first session began with two practice trials with feedback.

\section{Results}

In general, the results did not conform to predictions based on the use of a movementbased heuristic. Responses were not distorted in the direction that the pathway detoured from the euclidean line between its endpoints, nor did errors increase as the detour distance increased. Mode of exploration had little effect on these results.

Signed error was measured as the lesser of the two angular differences between the true stimulus angle and the observer's response.
Underestimations (responses within $180^{\circ}$ clockwise of the true value) were signed negatively; overestimations were signed positively. Figure 6 shows the errors for judgments of the direct line's angular position as a function of true direct angle. Each point corresponds to a different stimulus. The striking linearity of the function indicates why stimuli are not plotted separately for each level of the region variable. Figure 7 shows corresponding results for detour-line judgments.

Clearly, error for both types of judgments (direct and detour line) is a linear function of the true angle, with no effect on detour distance. As a movement-based strategy did not appear to be used in judging position, additional analyses were performed. The slopes and $y$ intercepts of the error versus true angle functions were considered to eval-

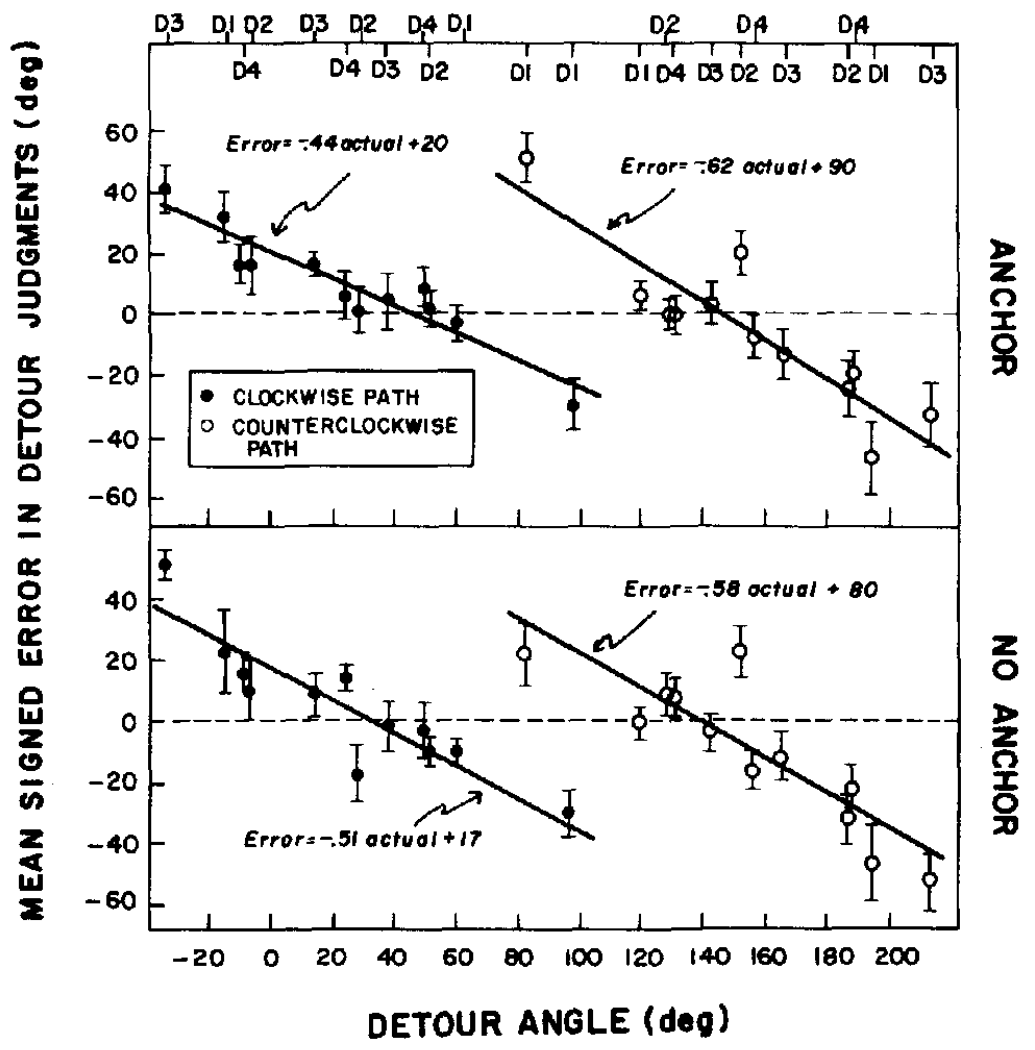

Figure 7: Experiment 5: Mean signed errors in judgments of angular position of the detour line, as a function of the true detour angle, for each mode of exploration (anchor, no anchor). (Detour distance is indicated as in Figure 6. Bars indicate one standard error of the mean. Separate functions are shown for the clockwise and counterclockwise pathway directions.) 
uate the possibility that a nonmovementbased, spatial referent strategy was used. For the curved pathways, the effect of pathway direction depended on the type of judgment. For judgments of the direct line (Figure 6), error values for clockwise and counterclockwise pathways fell along a single function. (The $r^{2}$ values were .94 and .92 in the anchor and no-anchor conditions, respectively.) The slope of that function was steeper in the noanchor condition, $F(1,18)=5.11, p<.05$. In contrast, for the detour-line judgments (Figure 7) there were two distinct functions relating error to true angle, one for each pathway direction. These functions had different intercepts, $F(1,18)=45.8, p<.001$. (The $r^{2}$ values for the clockwise and counterclockwise functions were .88 and .81 in the anchor condition and .81 and .77 in the noanchor condition.) There were no gender effects.

To compare the straight pathways with the curved ones, additional analyses were performed on the direct-line judgments (Figure 6). This time the pathway direction factor was replaced with "pathway type" (curved clockwise vs. curved counterclockwise vs. straight). The straight-line paths lay along a different function from the curved; in the analyses of slopes and intercepts, the pathway type factor produced $F \mathrm{~s}(2,36)=29.4$ and $34.9, p s<.001$, respectively. Although this may indicate an effect of movement, it seems likely to be mediated by the greater memory demands of following curved pathways.

\section{Experiment 6}

Experiment 5 generally failed to confirm the expectation that movements involved in haptic exploration would distort the perception of inferred position, as they had the perception of inferred distance in Experiments 1-4. Neither the distance that a pathway deviated nor its direction of deviation from the inferred direct line affected judgments of the orientation of that line. Instead, the results of Experiment 5 suggested the use of a nonmovement-based, spatial-referent heuristic for encoding position information. The spatial heuristic is indicated, in particular, by the linear functions relating error to the true angle. In terms of this heuristic, the functions in Figures 6 and 7 can be more meaningfully expressed as

$$
\text { Error }=a(\text { true angle }-b),
$$

where $a$ is the slope of the function(s) in each figure and $b$ is the corresponding $x$ intercept (i.e., the judged angle that is perceived with zero error). As this expression indicates, error was roughly a constant fraction (given by the slope) of the departure of the true stimulus angle from another angle $b$. If subjects judged position by first computing the deviation of the judged line from an implicit axis at $b$, and then moved the pointer away from that axis some constant fraction of that deviation, a linear error function like that observed would be obtained.

By this reasoning, the slope of the error function indicates the extent to which the implicit axis was relied upon: the steeper the slope, the more the response deviated toward that axis and the greater the error. The results of Experiment 5 indicate, then, that observers relied more upon implicit spatial axes when examining curved as compared with straight paths. Further, they indicate that in judgments of the direct line, an anchor produced slightly less reliance upon a spatial axis. The $x$ intercept of the error function indicates the position of the implicit axis that was used. The above analyses therefore suggest that the mode of exploration and pathway direction did not affect the axis used to make direct-line judgments (which was at about $90^{\circ}$ ), but that the axis used for judgments of the detour angle varied with pathway direction (in the vicinity of $45^{\circ}$ and $135^{\circ}$ for detour-line judgments with the clockwise and counterclockwise pathway directions, respectively).

One might conclude from this latter finding that the direction of movement influenced performance by dictating which spatial axis to use in judging the detour point's position. Experiment 6 tested an alternative to this movement-based strategy. It derives from the observation that the distribution of detour angles in Experiment 5 varied with pathway direction, that is, clockwise pathways were mostly less than $90^{\circ}$ and centered around $45^{\circ}$, and counterclockwise pathways were mostly greater than $90^{\circ}$ and centered around $135^{\circ}$. If subjects had learned about this very natural arrangement (during practice trials 
or early in the experiment), they might have used implicit spatial axes in the manner indicated by the results. (The low variability indicates that the arrangement was learned early and the spatial heuristic used consistently, if at all.)

To test this alternative explanation, the relative positions of direct and detour angles were reversed in Experiment 6 . Now the detour angles were distributed around $90^{\circ}$, and the distribution of direct angles varied with pathway direction; that is, clockwise pathways were associated with direct angles predominantly greater than $90^{\circ}$, and counterclockwise pathways were associated with direct angles less than $90^{\circ}$. If subjects tend to hone in on spatial axes that reflect the general arrangement of judged angles and to refer to these axes when making their judgments, we should find that the functions relating error to direct angle now vary with pathway direction, and those measuring error for detour judgments do not-the reverse of the pattern in Experiment 5.

\section{Method}

The naive observers were 9 male and 11 female students in introductory psychology at UCSB; all subjects were normally sighted. The stimuli were similar in design to those of Experiment 5, with the following changes. There were only two values of detour distance, 7.9 and $15.2 \mathrm{~cm}$. The corresponding pathway lengths were 29.3 and $50.9 \mathrm{~cm}$, which are 1.5 times (cf. 2 times in Experiment 5) the length of the S-P1-P2-E path shown in Figure 5. Pairs of pathways differing in the direction factor were related as shown in Figure 8. For each value of detour angle, there was a clockwise and counterclockwise path that were reflections of one another around the FE axis. These had the same points $E$ and $F$ (and thus the same detour line), but approached it from opposite directions.

The stimuli comprised 12 pathways (six mirror-image pairs) whose detour angles fell within $0-90^{\circ}$ and 12 whose detour angles fell within $90-180^{\circ}$. The position of the direct lines varied within $\pm 60-83^{\circ}$ of the detour lines. (The detour and direct angles used and corresponding detour-distance values are shown in Figures 9 and 10.) Each observer took part in 2 practice and 48 regular trials over one or two sessions lasting approximately 1 to $1 \mathrm{l} / 2 \mathrm{hr}$. Only the no-anchor mode of exploration was used. Each stimulus was presented twice, once with the detour-line judgment and once with the direct-line judgment, in random order. Observers were told which judgment to make after exploring the pathway.

\section{Results}

The results are shown in Figures 9 and 10. As in Experiment 5 (although the fits were

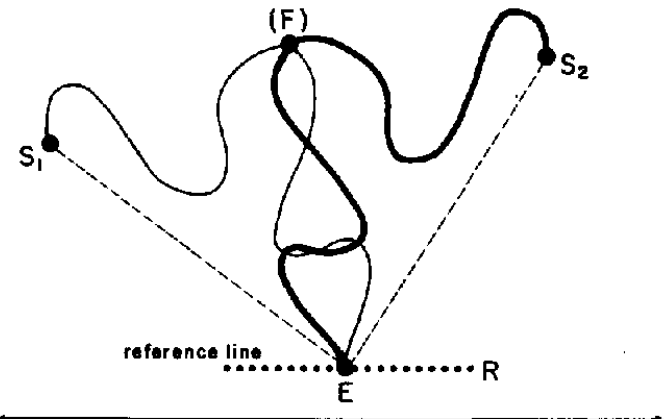

(Table Edga)

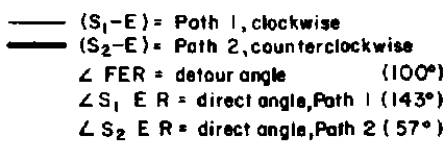

Figure 8. Experiments 6 and 7: Sample pair of configurations resulting from superimposition of stimuli that are reflections about a common detour line.

weaker), error was a linear function of the true angle judged. More important, reversal of the distributions of detour and direct angles led to a reversal of the previously obtained results. For the detour judgment, the values for both pathway directions lay along a single function $\left(r^{2}=.72\right)$. For the direct judgment, the clockwise and counterclockwise pathway directions produced different functions $\left(r^{2}=\right.$ .41 and .49 , respectively). These observations were confirmed by ANOVA on the slopes and intercepts, with judgment (detour, direct), pathway direction, and gender as factors. There were no significant effects on slopes. The intercepts of the functions differed as a function of pathway direction, $F(1,18)=$ $6.25, p<.05$, but only for the direct-line judgments- $F(1,18)=6.43, p<.05$ for the Judgment $\times$ Direction interaction.

Together with Experiment 5, these results indicate that subjects use implicit spatial axes rather than a movement-based heuristic in judging position. A spatial axis represents the general location of a group of angles (e.g. detour angles on clockwise-directed pathways). The influence of movement is therefore quite indirect. Where groups of angles associated with different directions of movement tend to have different locations in the plane, judgments of those angles will refer to different spatial axes. 


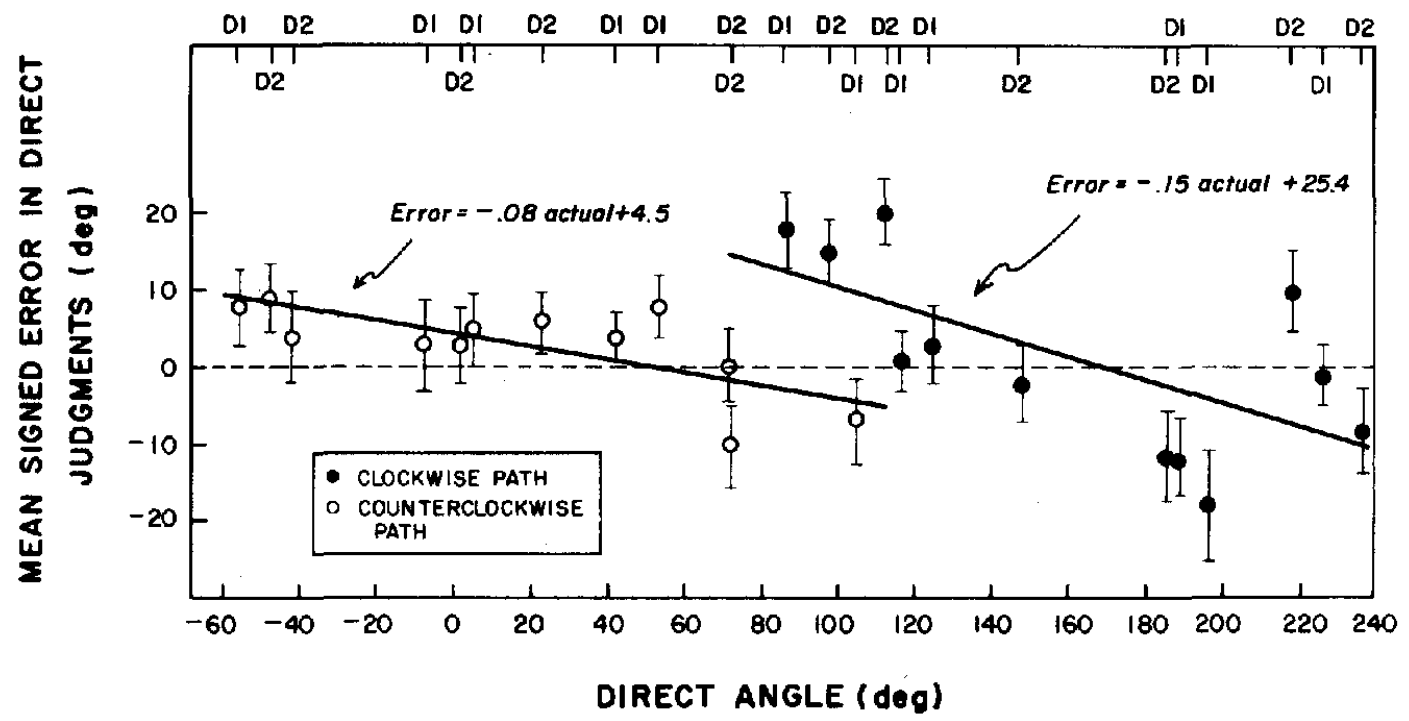

Figure 9. Experiment 6: Mean signed errors in direct-line judgments as a function of true direct angle; bars indicate one standard error of the mean. (The symbol at the top indicates the detour distance value for the corresponding stimulus, D1 $=7.9 \mathrm{~cm}, \mathrm{D} 2=15.2 \mathrm{~cm}$. Separate functions are shown for clockwise and counterclockwise pathway directions.)

\section{Experiment 7}

Experiment 7 attempted to eliminate the use of the spatial heuristic just described, to determine whether movement-related variables (i.e., detour distance and pathway di- rection) would then affect judgments of spatial position. Both detour and direct angles were distributed throughout the $360^{\circ}$ plane, so that it was impossible to approximate their general location with any one axis.

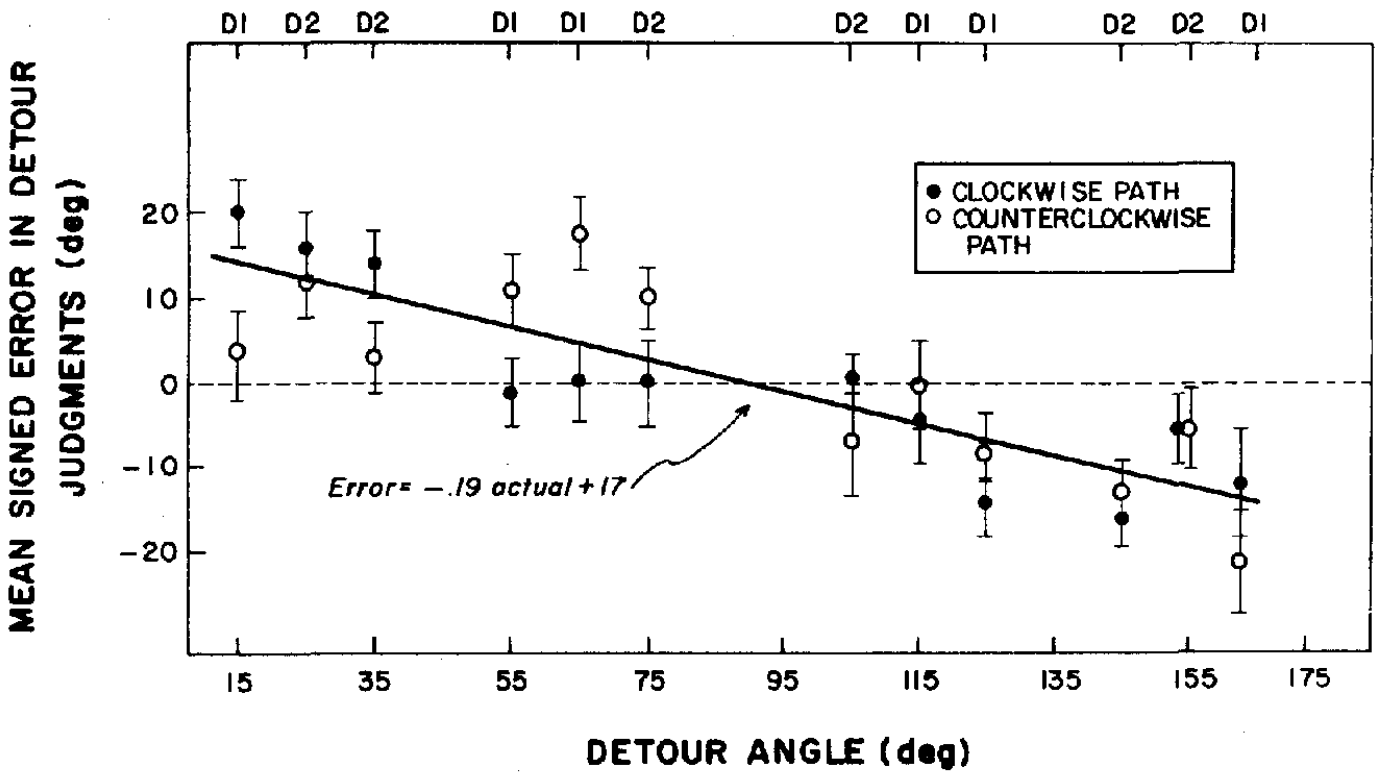

Figure 10. Experiment 6: Mean signed errors in detour-line judgments as a function of true detour angle; bars indicate one standard error of the mean. (Detour distance is indicated as in Figure 9.) 
Table 5

Experiment 7: Mean Error and Standard Error of the Mean by Gender, Detour Distance (in Centimeters), and Direction

\begin{tabular}{lrllllll} 
& \multicolumn{6}{c}{ Detour distance (cm) } \\
\cline { 2 - 7 } Direction & 4.1 & $S E$ & 7.9 & $S E$ & 15.2 & $S E$ \\
\hline Females & & & & & & \\
$\begin{array}{c}\text { Clockwise } \\
\text { Counter- }\end{array}$ & -3.8 & 4.2 & 3.9 & 1.8 & 7.6 & 3.7 \\
$\begin{array}{c}\text { clockwise } \\
\text { Males }\end{array}$ & 12.2 & 2.7 & 0.9 & 1.9 & 5.0 & 3.3 \\
$\begin{array}{c}\text { Clockwise } \\
\text { Counter- } \\
\text { clockwise }\end{array}$ & -4.1 & 3.5 & 1.5 & 3.4 & 0.7 & 2.7 \\
\hline
\end{tabular}

\section{Method}

Observers. The normally sighted naive observers were 12 male and 8 female students in introductory psychology at UCSB.

Stimuli. The stimuli were the same pathways used in Experiment 6, reoriented, plus six mirror-image pairs having a detour-distance value of $4.1 \mathrm{~cm}$ and a pathway length of $18.3 \mathrm{~cm}$. Pathways departed from the start point in either the clockwise or counterclockwise direction, where the end point was the center of the clock. The stimuli were oriented so that the detour angles fell within six regions that divided the $360^{\circ}$ plane into $60^{\circ}$ segments. For each detour distance, one pair of stimuli with a common detour line fell in each region. The direct angles were within $\pm 40-83^{\circ}$ of the detour angles. Each observer was given the 36 stimuli in a random order in one session that began with two practice trials.

Procedure. The procedure was like that of the noanchor, detour judgment trials of Experiment 5; neither the direct judgment nor the anchor condition was used.

\section{Results}

The results indicate that when a spatial heuristic is ineffective, the distance and direction of movement still do not bias judgments of position. Table 5 shows the mean signed error over observers and the standard error of the mean for each condition. Although there were effects of critical movement-related variables, that is, detour distance and pathway direction, these were unsystematic and attributable to stimulus variations. Each combination of direction, distance, and region corresponded to a unique pathway, and different pathways produced different values of signed errors, leading to a three-way interaction, $F(10,180)=4.68, p<.001$, a Direction $\times$ Distance interaction, $F(2,36)=3.46, p<$ .05 , and a region effect, $F(5,90)=2.35, p<$
.05. The very tight configurations resulting from a detour distance of $4.1 \mathrm{~cm}$ were particularly error-prone. This was especially true of one such configuration, in which the position of the detour point was clearly ambiguous. When these stimuli were eliminated from the analysis, there were no significant effects whatsoever. Effects of gender and the Gender $\times$ Distance $\times$ Direction interaction, $F(1,18)=5.23$ and $F(2,36)=5.80, p s<$ .05 , were also observed in the overall analysis but vanished with the elimination of the 4.1cm detour pathways.

\section{General Discussion}

The results of the current experiments indicate that haptic perceptions of distance and position both rely on encoding heuristics and that these perceptions, as a result, are subject to different forms of distortion. The nature of the heuristic appears to vary with the encoded spatial attribute.

Experiments 1-4 indicate the use of movement-based heuristic when inferring the euclidean distance between two points on a curved line. As pathway extent increased, the euclidean distance between the start and end points was increasingly overestimated by both sighted and blind observers. This pathway distortion effect was more pronounced in congenitally blind observers than adventitiously blind, suggesting that visual experience aids in inferring spatial extent from haptic exploration.

One interpretation of the distance distortion effect is that observers based their estimates of length on the duration of their finger movements. Such temporal influences on judgments of extent have been noted previously (Wapner, Weinberg, Glick, \& Rand, 1967; Wong, 1977), particularly in the "tau" effect (e.g., Scholtz, 1924), which is a tendency for judgments of the spatial distance between two stimuli to increase with their temporal distance. Another interpretation, similar to accounts of the filled-space illusion, is that subjects used the spatial extent of the explored pathway to infer the euclidean distance. The present data cannot, however, discriminate between distortions mediated by time or space and those attributable more directly to movement. 
In contrast to the distance judgments, people appeared to use a heuristic that is not based on movement when judging position; that is, they used one that referred positions to implicit spatial axes in the pattern plane. Similar heuristics have been found with visual displays (Tversky, 1981). Errors resulted because observers' judgments were pulled toward these axes by some roughly constant proportion of the departure of the direct line from the implicit axis. Variables manipulating observers' exploratory movements had only. indirect effects on their errors, influencing their choice of spatial referents.

What can be said regarding the route versus survey map distinction from these results? If observers built up a route map of the pathway from haptic exploration and used that map to answer questions about the inferred euclidean line, their judgments should be directly related to the route of exploration; that is, movement-related distortions should occur. The experiments on position judgments are clearly inconsistent with this account; in fact, the use of implicit spatial axes segregating regions of the plane suggests a survey representation. The judgments of distance, however, appear more in line with a route map interpretation. Alternatively, it remains possible that observers built up a distorted survey map from their movements. With the current data, caution must be exercised when considering a route map versus survey map interpretation. Whether surveylike or routelike, what is clearly indicated is that movement played a role in building the representation used for judging distance by both sighted and blind individuals and implicit reference axes played a role in the representation used for estimating position.

Further work is needed to clarify the conditions under which movement-dependent and movement-independent strategies will be used. However, the results of the present studies are immediately relevant to tangible graphics displays. In revealing certain sources of errors, our results have implications both for the design of such graphics and for their optimal use.

It should be noted that the present inferences about tangible graphics must for now be restricted to the curved, irregular sort of figures used here. However, despite this caveat, we have demonstrated specific sources of distortion in haptic spatial perception and can suggest means by which they might be reduced in an applied setting.

With regard to design, one message is that the size of a graphics configuration is of critical importance in determining the accuracy with which it communicates spatial information; moreover, optimal size may vary with the nature of the information to be communicated. In Experiments 1-4, smaller displays were less conducive to errors in distance estimation, which may be because of their making smaller demands on memory or may simply reflect Weber's law. However, in Experiment 7, smaller tightly curved pathways yielded markedly high errors in position judgments, which may reflect limits on "haptic acuity." Thus, size may trade off with other factors, and optimal size should be empirically determined in the context of application. A second message from the experiments on position is that tangible graphics should provide explicit referents (points, lines), to reduce distortions resulting from an arbitrary spatial-referent strategy (see also Lederman \& Campbell, 1982).

With respect to the most effective means of exploring tangible graphics displays, the present experiments suggest first that the user of a display should not be asked to ascertain a variety of spatial information simultaneously. This is indicated by the reduction in (but note, not elimination of ) error when subjects had to prepare for one versus two judgments in Experiments 1-4. Surprisingly, the use of an anchor in both sets of studies did not consistently reduce overall error, and it certainly did not eliminate (although it sometimes reduced) the distortions due to either movement-based or spatial heuristics. Furthermore, when the use of an anchor did have a positive effect, it extended only to judgments about the straight line between the fingers and not the pathway actually traversed (i.e., judgments of euclidean but not pathway distance in Experiments 1-4; direct-line but not detour-line position in Experiment 5). Thus, use of an anchor should be recommended only when information about its position is directly relevant to the judgment being made, and even then it appears of limited value.

In conclusion, our results suggest that there is flexibility in the heuristics used to encode 
pattern information from haptic exploration. When judging distance, our observers appeared to use a movement-based strategy; when judging position, they relied on implicit spatial axes. The latter strategy has also been demonstrated with visual pattern encoding, suggesting that vision and touch can have encoding heuristics in common. Could vision, like touch, also make use of a movementbased heuristic? It is possible that movement might play a strategic role in visual encoding of large-scale patterns that require multiple fixations and eye movements in order to be viewed. In this case, vision would more closely resemble haptic processing of small-scale space, in that movement would be intrinsic to pattern exploration.

\section{References}

Berla, E. (1982). Haptic perception of tangible graphics displays. In E. Schiff \& E. Foulke (Eds.), Tactual perception: $A$ sourcebook (pp. 364-386). New York: Cambridge University Press.

Book, A., \& Garling, T. (1981). Maintenance of orientation during locomotion in unfamiliar environments. Joumal of Experimental Psychology: Human Perception and Performance, 7, 995-1006.

Brambring, M. (1976). The structure of haptic space in the blind and sighted. Psychological Research, 38, 283302.

Cashdan, S. (1968). Visual and haptic form discrimination under conditions of successive stimulation. Journal of Experimental Psychology, 76(2, Pt. 1), 221-224.

Cleaves, W. T., \& Royal, R. W., (1979). Spatial memory for configurations by congenitally blind, late blind, and sighted adults. Journal of Visual Impairment and Blindness, 73(1), 13-19.

Dodds, A. G., Howarth, C. I., \& Carter, D. C. (1982). The mental maps of the blind: The role of previous visual experience. Journal of Visual Impairment \& Blindness, 76(1), 5-12.

Downs, R. M., \& Stea, D. (1977). Maps in minds: Reflections on-cognitive mapping. New York: Harper \& Row.

Ittelson, W. (1973). Environment perception and contemporary perceptual theory. In W. H. Ittelson (Ed.), Environment and cognition. New York: Seminar Press.

Kerr, N. H. (1983). The role of vision in "visual imagery" experiments: Evidence from the congenitally blind. Journal of Experimental Psychology: General, 112, 265-277.

Kosslyn, S. M., Pick, H. L., Jr., \& Fariello, G. R. (1974). Cognitive maps in children and men. Child Development, 45, 707-716.

Lederman, S. J. (1979). Tactual mapping from a psychologist's perspective. Bulletin of the Association of Canadian Map Libraries, 32, 21-25.

Lederman, S. J., \& Campbell, J. (1982). Tangible graphs for the blind. Human Factors, 24(1), 85-100.

Lederman, S. J., \& Taylor, M. M. (1969). Perception of interpolated position and orientation by vision and active touch. Perception \& Psychophysics, 6, 153-159.

Liben, L. S., Patterson, A. H., \& Newcombe, N. (Eds.). (1981). Spatial representation and behavior across the life span. New York: Academic Press.

Lobb, H. (1965). Vision versus touch in form discrimination. Canadian Journal of Psychology, 19(3), 175187.

Millar, S. (1975). Spatial memory by blind and sighted children. British Journal of Psychology, 66, 449-459.

Millar, S. (1976). Spatial representation by blind and sighted children. Journal of Experimental Child Psychology, 12, 460-479.

Millar, S. (1981). Self-referent and movement cues in coding spatial location by blind and sighted children. Perception, 10, 255-264.

Nelson, T. O., \& Chaiklin, S. (1980). Immediate memory for spatial location. Journal of Experimental Psychology: Human Learning and Memory, 6, 529-545.

O'Connor, N., \& Hermelin, B. (1978). Seeing and hearing and space and time. New York: Academic Press.

Rieser, J. J., Guth, D. A., \& Hill, E. W. (1982). Mental processes mediating independent travel: Implications for orientation and mobility. Journal of Visual Impairment and Blindness, 76, 213-218.

Rieser, J. J., Lockman, J. J., \& Pick, H. L., Jr. (1980). The role of visual experience in knowledge of spatial layout. Perception and Psychophysics, 28(3), 185-190.

Sadalla, E. K., Staplin, L. J., \& Burroughs, W. J. (1979). Retrieval processes in distance cognition. Memory and Cognition, 7(4), 291-296.

Schiff, W., \& Foulke, E. (Eds.). (1982). Tactual perception: A sourcebook. New York: Cambridge University Press.

Sherman, R. C., Croxton, J., \& Smith, M. (1979). Movement and structure as determinants of spatial representations. Journal of Nonverbal Behavior, 4(1), 27-39.

Sholtz, W. (1924). Experimentelle Untersuchungen uber die phenomenale Grosse von Raumstricken, die durch Sukzessiv-Darbietung zweier Reize begrenzt werden. Psychologische Forschung, 5, 219-272.

Taylor, M. M. (1961). Effect of anchoring and distance perception on the reproduction of forms. Perceptual \& Motor Skills, 12, 203-230.

Thorndyke, P. W. (1981). Distance estimation from cognitive maps. Cognitive Psychology, 13, 526-550.

Tversky, B. (1981). Distortions in memory for maps. Cognitive Psychology, 13, 407-433.

Wapner, S., Weinberg, J., Glick, J. A., \& Rand, G. (1967). Effect of speed of movement on tactual-kinesthetic perception of extent. American Journal of Psychology, $80(4), 608-613$.

Wong, T. S. (1977). Dynamic properties of radial and tangential movements as determinants of the haptic horizontal-vertical illusion with an L figure. Journal of Experimental Psychology: Human Perception and Performance, 3(1), 151-164.

Woodworth, R. (1938). Experimental-psychology. New York: Holt.

Worchel, P. (1951). Space perception and orientation in the blind. Psychological Monographs, 65. (Whole No. 332).

Received March 16, 1984

Revision received June 5, 1984 